Article

\title{
Residual Stress, Microstructure and Mechanical Properties in Thick 6005A-T6 Aluminium Alloy Friction Stir Welds
}

\author{
Xiaolong Liu ${ }^{1,+}, \mathrm{Pu} \mathrm{Xie}^{2,+}{ }^{-}$, Robert Wimpory ${ }^{3}$, Wenya Li ${ }^{4}$, Ruilin Lai ${ }^{5}$, Meijuan Li ${ }^{1}$, \\ Dongfeng Chen ${ }^{1}$, Yuntao Liu ${ }^{1}$ and Haiyan Zhao ${ }^{6, *}$ \\ 1 Department of Nuclear Physics, China Institute of Atomic Energy, Beijing 102413, China \\ 2 CRRC Changchun Railway Vehicles Co. Ltd., Changchun 130000, China \\ 3 Helmholtz-Zentrum Berlin für Energie und Materialien, Hahn Meitner Platz 1, 14109 Berlin, Germany \\ 4 Shanxi Key Laboratory of Friction Welding Technologies, School of Materials Science and Engineering, \\ Northwestern Polytechnical University, Xi'an 710072, China \\ 5 Department of Mechanical and Electrical Engineering, Central South University, Changsha 410083, China \\ 6 State Key Laboratory of Tribology, Department of Mechanical Engineering, Tsinghua University, \\ Beijing 100084, China \\ * Correspondence: hyzhao@tsinghua.edu.cn; Tel.: +86-10-6278-4578 \\ + These authors contributed equally to this work and should be considered as co-first authors.
}

Received: 3 July 2019; Accepted: 18 July 2019; Published: 21 July 2019

\begin{abstract}
Plates (37 mm thick) of 6005A-T6 aluminum alloy were butt joined by a single-sided and double-sided friction stir welding (FSW). The 3D residual stresses in the joints were determined using neutron diffraction. The microstructures were characterized by a transmission electron microscope (TEM) and electron backscatter diffraction (EBSD). In the single-sided FSW specimen, there were acceptable mechanical properties with a tensile strength of $74.4 \%$ of base metal (BM) and low residual stresses with peak magnitudes of approximately $37.5 \%$ yield strength of BM were achieved. The hardness is related to the grain size of the nugget zone (NZ), and in this study, precipitations were dissolved due to the high heat input. In the double-sided FSW specimen, there were good mechanical properties with a tensile strength of $80.8 \%$ of $\mathrm{BM}$, but high residual stresses with peak magnitudes of approximately $70 \%$ yield strength of BM were obtained. The heat input by the second pass provided an aging environment for the first-pass weld zone where the dissolved phases were precipitated and residual stresses were relaxed.
\end{abstract}

Keywords: residual stresses; friction stir welding; neutron diffraction; aluminium alloys; hardness; precipitation

\section{Introduction}

Aluminium alloy $6005 \mathrm{~A}$, a $\beta$-precipitation $\left(\mathrm{Mg}_{2} \mathrm{Si}\right)$ strengthened heat treatable alloy, is widely used in rail transportation industries due to its excellent corrosion resistance and extrusion characteristics $[1,2]$. The welding joints to connect the extruded sheets and plates are usually the weak regions since the welding heat input introduces the microstructural changes deteriorating the mechanical properties and residual stresses causing fatigue cracks and stress-induced corrosion [3,4]. Therefore, sound welding is required to join extruded aluminium alloy sheets and plates.

Friction stir welding is a solid-state joining technique, which involves both plastic and thermal deformations $[5,6]$. In this process, process parameters, such as tool rotation and traverse speeds, need to be optimized to get good quality joints. The effect of tool rotation and traverse speeds, on microstructural changes and residual stresses of friction stir welding (FSW) aluminium alloys, have 
been studied widely [1-4,7-34]. Simar et al. reported that the $\beta$ " originally present in the base metal (BM) fully dissolved in the nugget zone (NZ) and coarsened in the heat affected zone (HAZ) of 6005A-T6 aluminium FSW joint [1]. They also explained the softened region around the weld center. Dong et al. studied the effect of welding speed on microstructures and the mechanical properties of 6005A-T6FSW joints, reporting an increased tendency of tensile properties with increasing the welding speed [4]. Wang et al. concluded that the 6061-T6 aluminum FSW joints made at low welding speed exhibited lower residual stress, due to a change in microstructure and stress relaxation that occurred as a result of the longer heating time associated with the low welding speed [8]. Therefore, microstructure, mechanical properties and residual stresses should be considered together to obtain the optimized FSW process. However, most studies have focused on the effects of welding speed and rotation speed on either microstructures and mechanical properties, or residual stresses in aluminium sheets and thin plates.

Nonetheless, FSW has been applied to the production of large prefabricated aluminium panels in high speed railcars, which helps to reduce the weight and improve the integrity of aluminium sheets. To join thick 6005A aluminium plates using FSW, a better understanding of residual stresses and microstructure is required. However, the residual stresses and microstructures have not been studied in thick 6005A-T6 aluminium alloy plates joined by single-sided and double-sided FSW.

Among the methods of residual stress measurement, neutron diffraction can nondestructively characterize the 3D residual stress distribution of engineering materials [35,36]. The deep penetration capability of neutrons into most metallic materials makes neutron diffraction a powerful tool for determining residual stresses through welds. The E3 residual stress diffractometer at HZB is one such high-performance neutron residual stress instrument, capable of experimental measurement of 3D residual stress distributions [37]. This instrument was chosen to characterize the residual stresses in thick 6005A-T6 aluminium alloy FSWs.

In this work, thick 6005A-T6 aluminium alloy plates (37 mm thick) were studied to determine the single-sided and double-sided FSW residual stress distributions using neutron diffraction. In addition, microstructures and mechanical properties were studied to characterize welding behavior. This experimental study was carried out to understand the 3D residual stress distributions and microstructural changes. This study can be helpful in the design of welding strategies.

\section{Experimental Details}

\subsection{Materials}

The base metal used in this investigation was $37 \mathrm{~mm}$ thick 6005A-T6 aluminium alloy with the chemical composition and mechanical properties shown in Table 1. The dimensions of the 6005A-T6 test plates are shown in Figure 1.

Table 1. The chemical composition and mechanical properties of $6005 \mathrm{~A}$ aluminium alloy.

\begin{tabular}{ccccccccccccc}
\hline \multicolumn{1}{c}{ Chemical Composition (wt.\%) } & \multicolumn{3}{c}{ Mechanical Properties } \\
\hline $\mathrm{Mg}$ & $\mathrm{Si}$ & $\mathrm{Fe}$ & $\mathrm{Cu}$ & $\mathrm{Mn}$ & $\mathrm{Cr}$ & $\mathrm{Ti}$ & $\mathrm{Zn}$ & $\mathrm{Al}$ & $\begin{array}{c}\text { Yielding } \\
\text { Strength } \\
\text { (MPa) }\end{array}$ & $\begin{array}{c}\text { Tensile } \\
\text { Strength } \\
(\mathrm{MPa})\end{array}$ \\
\hline 0.54 & 0.62 & 0.19 & 0.07 & 0.14 & 0.01 & 0.01 & 0.02 & $\mathrm{Bal}$ & 250 & 200 \\
\hline
\end{tabular}

Further, FSW was carried out on a LM-FSW-5025 machine (China FSW Center, Beijing, China). For the single-sided FSW, the tool consisted of a $35 \mathrm{~mm}$ diameter shoulder with a pin length of $36.5 \mathrm{~mm}$ and a root diameter of $18 \mathrm{~mm}$. The single-sided FSW process was performed with a rotation speed of $350 \mathrm{rpm}$ and a traverse speed of $40 \mathrm{~mm} / \mathrm{min}$. The down force was approximately $8-9 \mathrm{kN}$. For the double-sided FSW, the tool consisted of a $32 \mathrm{~mm}$ diameter shoulder with a pin length of $18 \mathrm{~mm}$ and a root diameter of $14.4 \mathrm{~mm}$. To apply the second pass of the FSW, the plates were rotated around their 
welding axes after completing the first weld. All welding passes were conducted with a rotation speed of $650 \mathrm{rpm}$ and a traverse speed of $200 \mathrm{~mm} / \mathrm{min}$. The down force was approximately 13-14 kN.

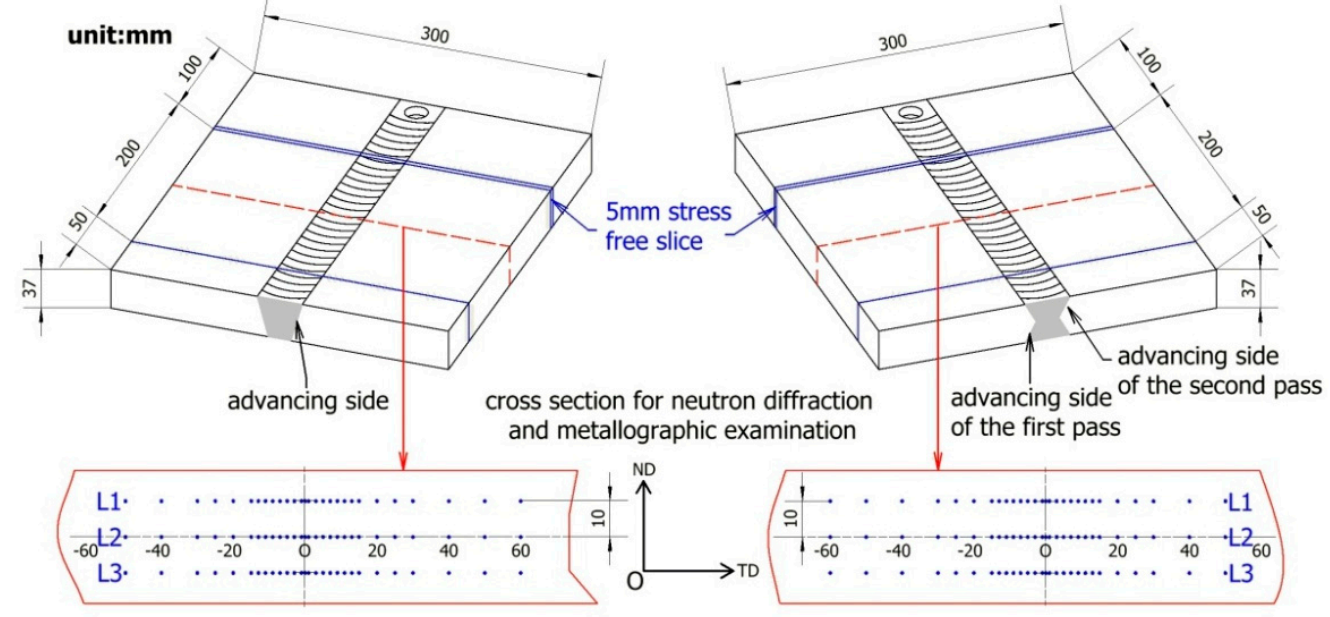

Figure 1. The layout of single-sided and double-sided friction stir welding (FSWs).

The temperature of the NZ was estimated using the following relation [38]:

$$
\frac{T}{T_{m}}=\mathrm{K}\left(\frac{w^{2}}{v \times 10^{4}}\right)^{\alpha}
$$

where $T_{m}$ is the melting temperature of $6005 \mathrm{~A}$ aluminium alloy $654{ }^{\circ} \mathrm{C}$, exponent $\alpha$ is a dimensionless constant selected as $0.05, \mathrm{~K}$ is a dimensionless constant selected as $0.7, v$ is the traverse speed and $\omega$ is the rotation speed [39]. According to Equation (1), the temperature of the nugget zone in the single-sided FSW is $431.4{ }^{\circ} \mathrm{C}$, while in the double-sided, FSW is $423.5^{\circ} \mathrm{C}$.

\subsection{Neutron Diffraction}

Due to the high penetration ability of thermal neutrons, neutron diffraction is an excellent engineering tool for providing 3D residual stresses nondestructively in bulk components. Therefore, neutron diffraction was applied to characterize the residual stresses in thick 6005A-T6 aluminium alloy FSWs, and was performed on the dedicated residual stress neutron diffractometer E3 at HZB, Germany.

As shown in Figure 1, the middle section with $200 \mathrm{~mm}$ in length was cut using electrical discharge machining (EDM, LA350, SSG, Suzhou, China) from the specimen for a neutron diffraction measurement. The longitudinal direction (LD), transverse direction (TD) and normal direction (ND) were assumed to be the principal directions in the bulk of the components and were measured as three orthogonal directions. The points along three lines, L1, L2 and L3, in the cross section were chosen to characterize the residual stresses, as shown in Figure 1. The diffraction peaks of the marked points were measured with the scattering vector parallel to three orthogonal directions. The peak positions, $2 \theta$, were analyzed using the least square Gaussian fitting method [40].

The measurements were made using the $\mathrm{Al}(311)$ Bragg reflection, which is the strongest diffraction reflection and also is weakly affected by intergranular strains [36]. The E3 is equipped with a perfectly bent $\mathrm{Si}(400)$ crystal monochromator providing a wavelength of $1.47 \AA$. Therefore, the $\mathrm{Al}(311)$ reflection was at a scattering angle of $2 \theta \sim 74^{\circ}$. Figure 2 shows the experimental setup on E3 for the measurement of the transverse component. The gauge volume was defined by an incident primary slit with $3 \mathrm{~mm}$ and a secondary radial collimator with $2 \mathrm{~mm}$. The height of the primary slit was set to $10 \mathrm{~mm}$ for transverse and normal measurements, and $3 \mathrm{~mm}$ for longitudinal measurements. 


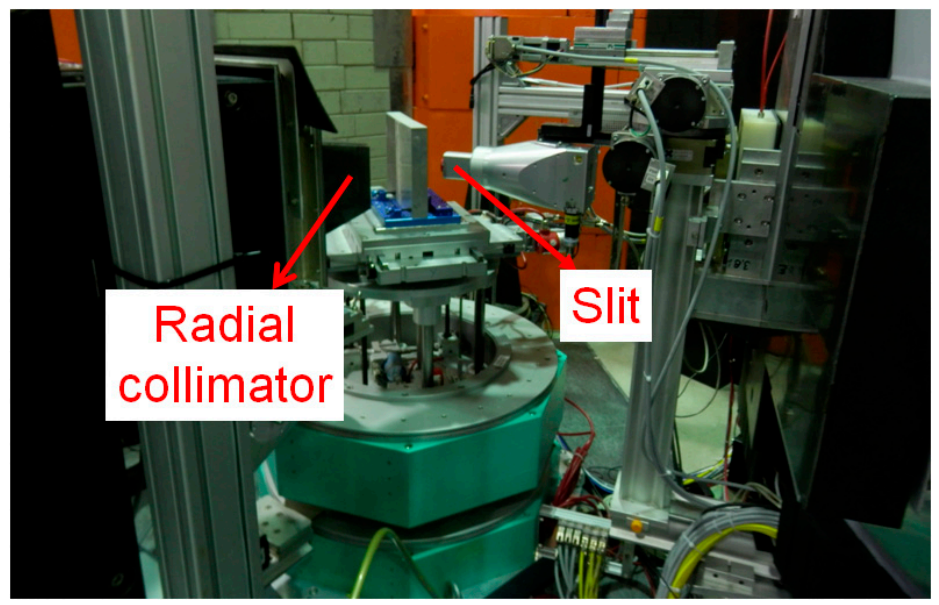

Figure 2. The experimental setup.

The elastic lattice strains $\varepsilon_{i}$ in the $i$-direction $(i=\mathrm{LD}, \mathrm{TD}, \mathrm{ND})$ were calculated using the following equation [36]:

$$
\varepsilon_{i}=\frac{d_{i}-d_{0}}{d_{0}}
$$

The elastic strains were converted to residual stresses $\left(\sigma_{\mathrm{LD}}, \sigma_{\mathrm{TD}}, \sigma_{\mathrm{ND}}\right)$ using the generalized Hooke's law [36]:

$$
\sigma_{i}=\frac{E_{h k l}}{1+v_{h k l}}\left[\varepsilon_{i}+\frac{v_{h k l}}{1-2 v_{h k l}}\left(\varepsilon_{\mathrm{LD}}+\varepsilon_{\mathrm{TD}}+\varepsilon_{\mathrm{ND}}\right)\right]
$$

where $i$ is the LD, TD or ND component corresponding to the three orthogonal directions. The diffraction elastic constants $\left(E_{311}\right)$ of $69 \mathrm{GPa}$ and Poisson's ratio $\left(v_{311}\right)$ of 0.35 were computed using the Kröner model via the software, IsoDEC [41].

To obtain a precise stress-free reference lattice parameter, $d_{0}$, is an important part of the diffraction-based, residual strain/stress experiment. To address a possible issue of $d_{0}$ variation due to microstructural changes, a full stress analysis was performed on 5-mm slices made by EDM from the specimen. The measurements were repeated in the same positions as for the specimen. Then, in an approximation of a biaxial stress state and the condition of the through thickness component (longitudinal in this case) to be zero $\left(\sigma_{\mathrm{LD}}=0\right)$, the calculation of the stress-free parameters was made according to the following equation:

$$
d_{0}=\frac{1-v_{h k l}}{1+v_{h k l}} d_{\mathrm{LD}}+\frac{v_{h k l}}{1+v_{h k l}}\left(d_{\mathrm{TD}}+d_{\mathrm{ND}}\right)
$$

As well as the TD and ND stress components in the slice as a by-product of the analysis,

$$
\sigma_{\mathrm{TD}}=\frac{E_{h k l}}{1+v_{h k l}}\left[\varepsilon_{\mathrm{TD}}-\varepsilon_{\mathrm{LD}}\right], \sigma_{\mathrm{ND}}=\frac{E_{h k l}}{1+v_{h k l}}\left[\varepsilon_{\mathrm{ND}}-\varepsilon_{\mathrm{LD}}\right] .
$$

\subsection{Microstructure Characterization}

The metallographic samples were cut perpendicular to the welding direction using EDM to avoid thermal degradation. The optical microstructure examination was performed on an Olympus microscope.

In order to compare the difference in precipitation, the microstructure examination in the NZ was conducted by a transmission electron microscope (TEM, Tecnai G2 F20, FEI, Hillsboro, OR, USA). The metallographic samples were polished down to a thickness of $80 \sim 100 \mu \mathrm{m}$. The final thickness reduction was obtained by electro-polishing with a $\mathrm{HNO}_{3}$ solution $\left(\mathrm{HNO}_{3} 30 \%\right.$ in volume in methanol at $\sim 30{ }^{\circ} \mathrm{C}$ under $9 \mathrm{~V}$ ). 
The electron backscatter diffraction (EBSD) samples were examined in a high resolution Philips XL30 field emission gun (FEG) SEM (Philips, Amsterdam, The Netherlands) interfaced to an HKL Channel EBSD orientation mapping system. The resulting EBSD orientation maps, with a step size of $0.1-0.25 \mu \mathrm{m}$ and an area of $145 \times 127 \mu \mathrm{m}$, were used to characterize the grain structures present in the NZ at three positions on cross sections along the weld center line, namely, the top (10 mm above the mid plane), the center (at the mid plane), and the bottom of the nugget (10 $\mathrm{mm}$ below the mid plane). The maps were processed using in house software (VMap) to determine the grain size.

\subsection{Mechanical Properties}

The hardness tests were performed using the Vicker hardness method, using a load of $500 \mathrm{~g}$ applied for $10 \mathrm{~s}$. Three lines were chosen on the transverse section of the welds with a distance of $1 \mathrm{~mm}$ between neighboring measured points, as shown in Figure 1. The specimens were cut to 3-mm slices to release the residual stress, which minimized the influence of residual stress on the hardness test.

The tensile tests on welded specimens were performed on the transverse, i.e., perpendicular to the welding direction. Eight samples were cut using EDM from the single-sided FSW and double-sided FSW. The transverse cross-section of the tensile samples is shown in Figure 3. These tensile samples were $25 \mathrm{~mm}$ thick, $6 \mathrm{~mm}$ wide and $200 \mathrm{~mm}$ long, with an initial gauge length of $100 \mathrm{~mm}$. The tensile test was carried out on a universal electronic tensile testing machine (MTS Landmark) with a crosshead moving speed of $2 \mathrm{~mm} / \mathrm{min}$. The range of load cell is $\pm 100 \mathrm{KN}$.

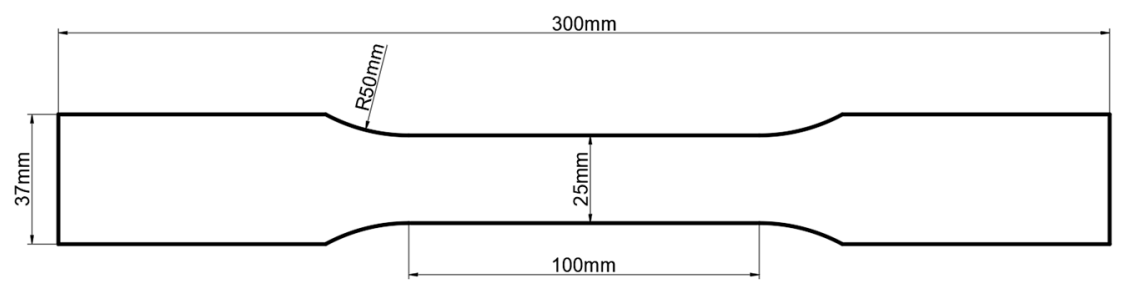

Figure 3. The layout of a tensile specimen.

\section{Results and Discussion}

Heat-treatable aluminium alloys derive much of their strength from the presence of fine precipitates. As residual stresses and microstructures are of great significance in determining weld performance, they were studied together for thick 6005A-T6 aluminium alloy FSWs.

\subsection{Microstructural Evolution}

Figure 4 shows the macrostructure of the 6005A-T6 single-sided and double-sided FSW joints. The NZ, thermo-mechanically affected zone (TMAZ), HAZ and BM are divided by the dotted lines. The TMAZ is more optically distinct on the advancing side and more diffuse on the retreating side in both specimens. The microstructures, including grain size and precipitation at the marked positions in Figure 4, are discussed further.

(a)

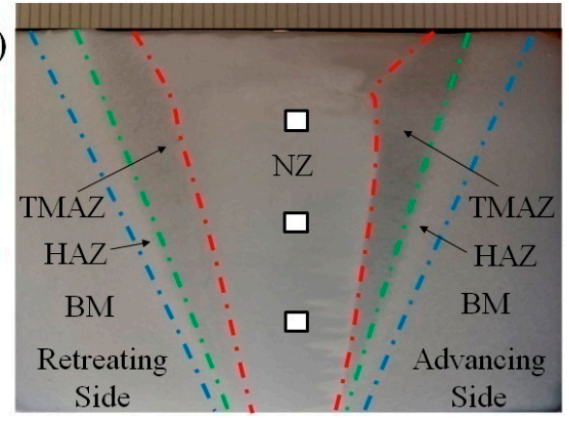

(b)

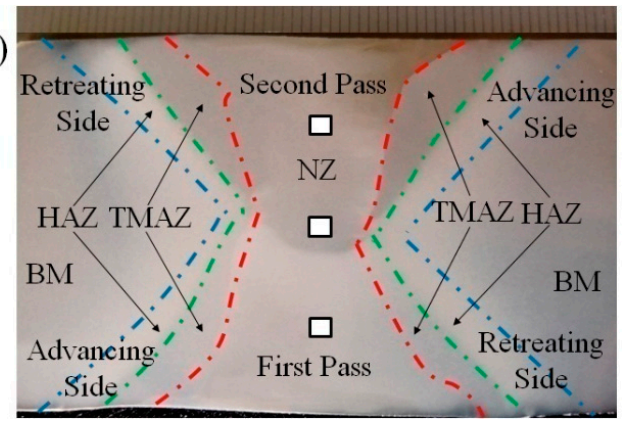

Figure 4. Macrographs (optical) of a single-sided FSW (a) and a double-sided FSW (b). 


\subsubsection{Features in the Single-Sided FSW}

Figure 5 shows the grain map and the corresponding grain size distribution, TEM and its diffraction pattern in the single-sided FSW. The average grain size in the NZ was 9.16, 8.49 and $7.38 \mu \mathrm{m}$ on L1, L2 and L3 line respectively. It is often suggested that the microstructure in the NZ is the result of continuous dynamic recrystallization supported by dynamic recovery [6]. The recrystallized grain size is mainly affected by the heat input in the welding process [6]. More heat input generated in the upper $\mathrm{NZ}$ and less heat input in the bottom NZ, which resulted in the larger grain size $(9.16 \mu \mathrm{m})$ in the upper $\mathrm{NZ}$ and smaller grain size $(7.38 \mu \mathrm{m})$ in the bottom NZ.

In order to study the microstructural evolution, the BM was observed by TEM, as shown in Figure 6. The BM contains a high density of fine hardening precipitates, as reported in the literature [6]. In the 6005A-T6 single-sided FSW, no precipitation was observed in the NZ. It is inferred that precipitations in the NZ were dissolved due to the friction heat and plastic deformation.

\subsubsection{Features in the Double-Sided FSW}

Figure 7 shows the grain map and the corresponding grain size distribution, TEM and its diffraction pattern in the double-sided FSW. The average grain size in the NZ was 7.48, 6.25 and $9.69 \mu \mathrm{m}$ on L1, L2 and L3 lines respectively. The grain size in the first pass is much larger than that in the second pass. No precipitation was observed in the NZ of the second-pass region and the middle region. As compared to the $\mathrm{BM}$, fewer precipitations were observed in the $\mathrm{NZ}$ of the first-pass region.
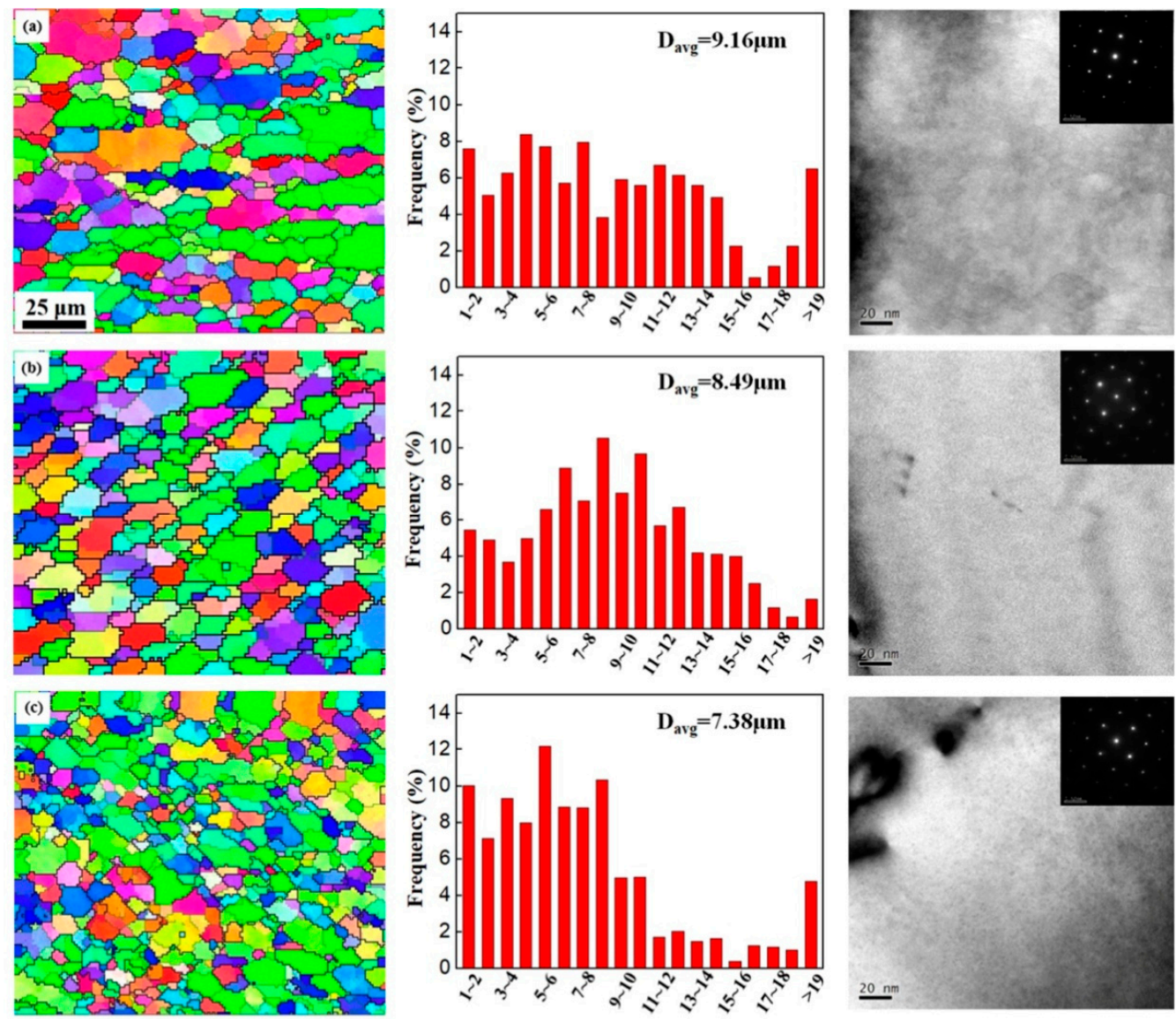

Figure 5. The grain map (on the left), grain size distribution (in the middle), TEM and diffraction pattern (on the right) of the NZ on L1 (a), NZ on L2 (b) and NZ on L3 (c) in the single-sided FSW. 

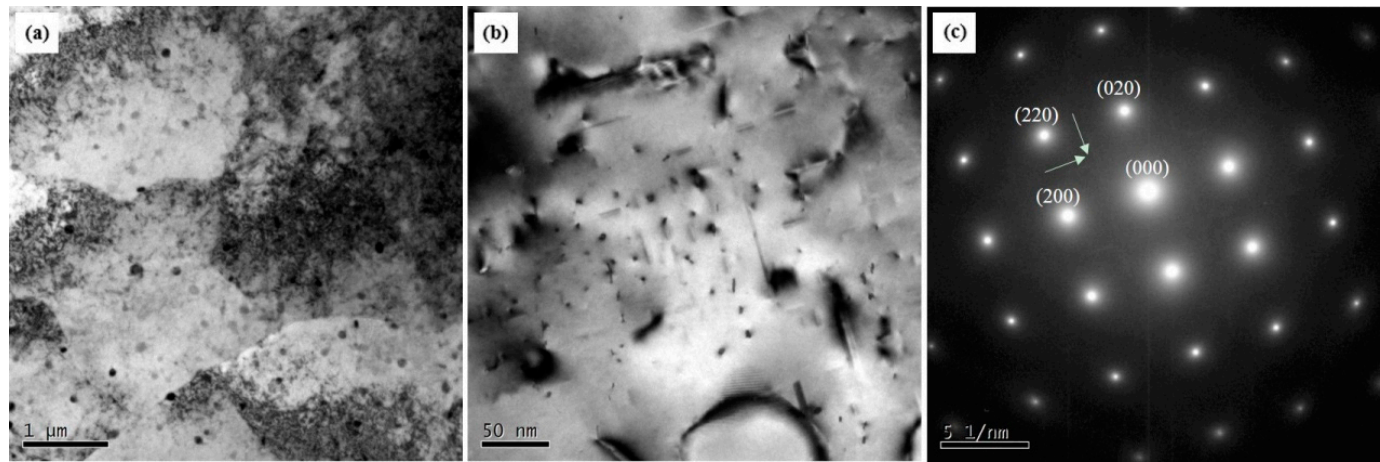

Figure 6. The microstructure of the base metal (BM) observed by SEM (a), TEM (b) and the diffraction pattern $(\mathbf{c})$.
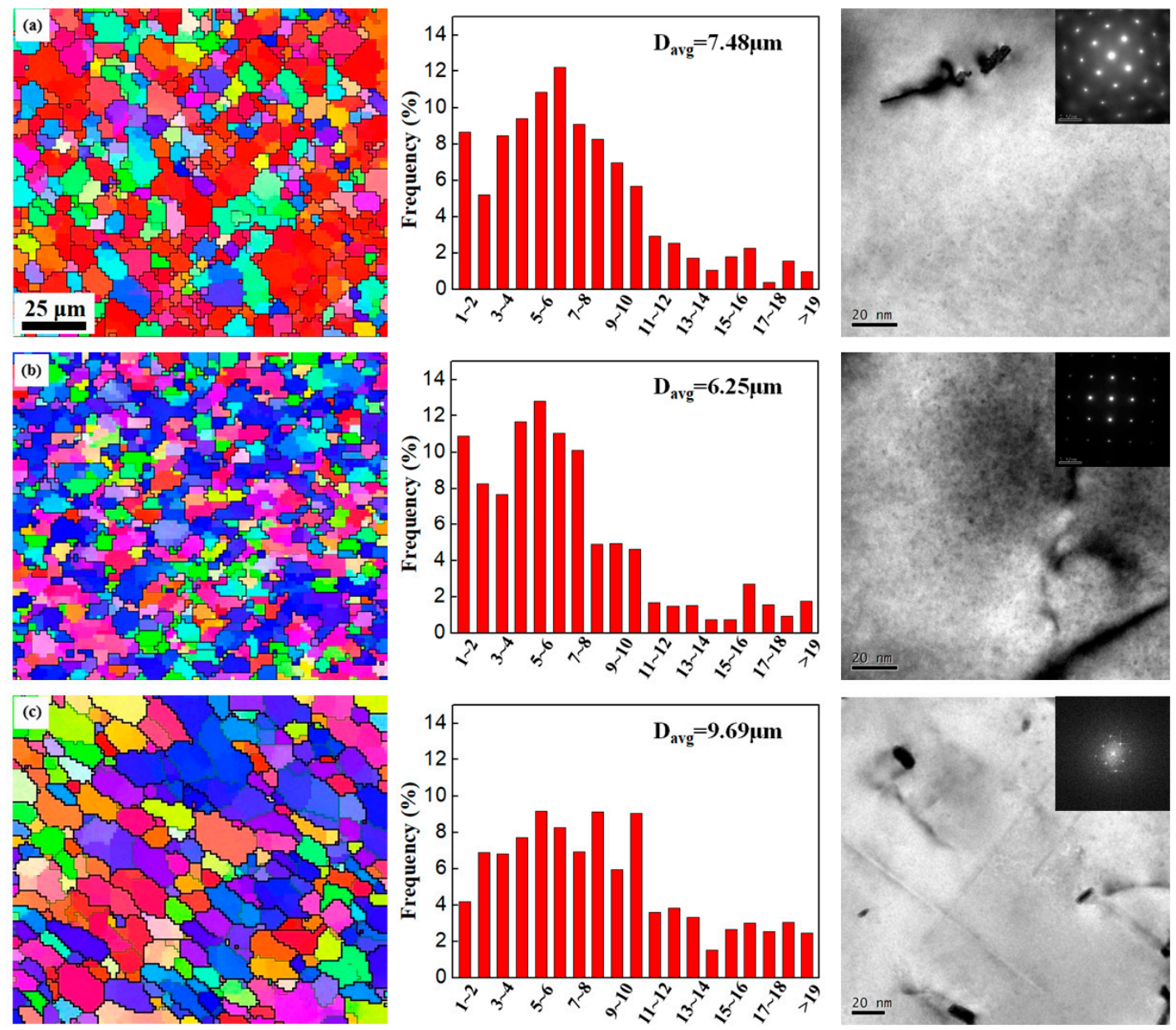

Figure 7. The grain map (on the left), grain size distribution (in the middle), TEM and diffraction pattern (on the right) of the NZ on L1 (a), NZ on L2 (b) and NZ on L3 (c) in the double-sided FSW.

The precipitations were dissolved in the second-pass NZ, while the precipitations were observed in the first-pass NZ. As the parameters were the same for the first and second pass, the authors inferred that the precipitations in the NZ were dissolved during the process of dynamic recrystallization in the first weld pass. The heat input by the second weld pass provided the aging temperature that the strengthening phases were precipitated in the first-pass NZ with grain growth occurring at the same time. 


\subsubsection{Comparison of Grain Size between Single-Sided and Double-Sided FSWs}

The grain size of the NZ in the single-sided FSW is larger than the second pass of the double-sided FSW. The temperature of the NZ in the single-sided FSW is $7.9^{\circ} \mathrm{C}$ higher than the double-sided FSW. The higher temperature is useful to activate the dynamic recrystallization and grain growth. This comparison verified the effect of the heat input on the recrystallized grain size.

\subsection{Mechanical Properties}

\subsubsection{Hardness Distribution}

Figure 8 shows the hardness profiles in the weld zone of single-sided and double-sided FSWs. The obtained profiles follow the general features with a central plateau and two valleys, which is a typical hardness behavior for all FSW heat treatable aluminium alloys [6].
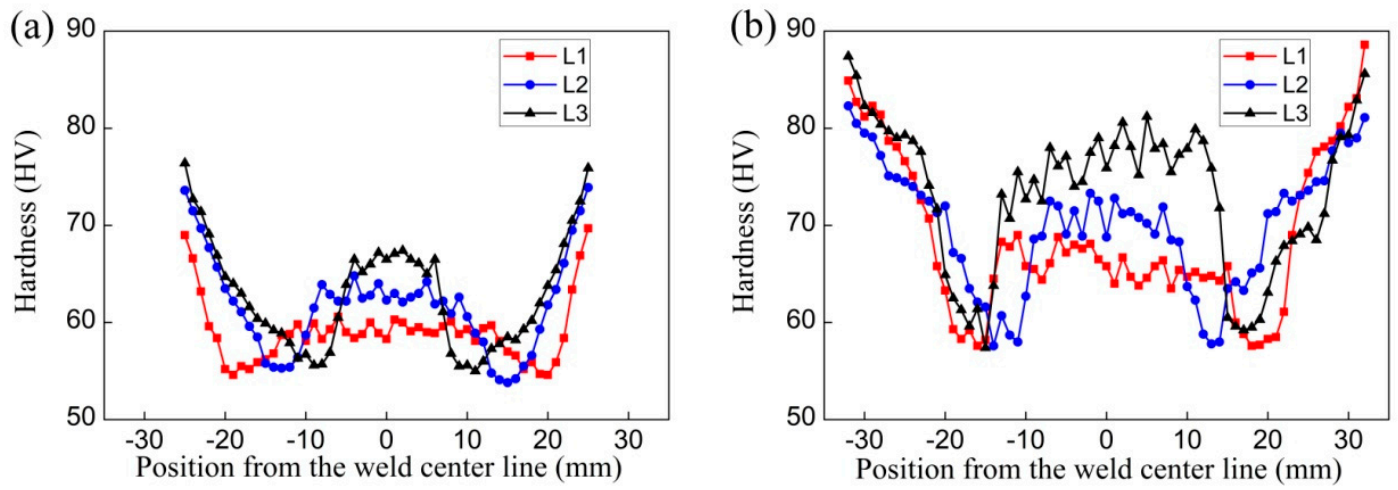

Figure 8. The hardness distribution in the single-sided FSW (a) and the double-sided FSW (b).

In the single-sided FSW, the minimum hardness on three lines is nearly the same with a value of approximately $54 \mathrm{HV}$ and all appear in the HAZ. The valleys on L1 line, L2 line and L3 line are located approximately 20,15 and $10 \mathrm{~mm}$ away from the weld center, respectively. The distance between two valleys decreases towards the bottom of the weld, which corresponds to the shape of the rotating pin. The average hardness of the NZ (central plateau) is 59.2, 62.8 and $66.4 \mathrm{HV}$ on L1, L2, L3 lines, respectively. The hardness in the NZ increases in the order of the upper, middle and bottom regions. With the absence of precipitation in the NZ, fine grains usually benefit the strength [6]. Therefore, the hardness of $\mathrm{NZ}$ in the bottom region (grain size $7.38 \mu \mathrm{m}$ ) is $12.2 \%$ larger than that in the upper region (grain size $9.16 \mu \mathrm{m}$ ).

In the double-sided FSW, the hardness is generally larger than the single-sided FSW. The minimum hardness on three lines is nearly the same with approximately $58 \mathrm{HV}$ and all appear in the HAZ. The valleys on L1 line, L2 line and L3 line are located approximately 18, 13 and $17 \mathrm{~mm}$ away from the weld center, respectively. The average hardness of the NZ (central plateau) is 66.0, 71.1 and $76.9 \mathrm{HV}$ on L1, L2 and L3 lines respectively. The hardness of the middle NZ is 7.7\% larger than that of the second-pass NZ. This is caused by the grain size in the middle NZ with $6.25 \mu \mathrm{m}$ and in the second-pass $\mathrm{NZ}$ with $7.48 \mu \mathrm{m}$. The hardness of the first-pass NZ is approximately $16.5 \%$ larger than the second-pass NZ. The second-pass NZ has no precipitation and smaller grains, while the first-pass NZ has a small quantity of precipitations and larger grains. It is concluded that the strengthening precipitations overwhelm larger grain size in controlling the hardness.

\subsubsection{Tensile Strength}

The tensile strength of a single-sided FSW and a double-sided FSW was $186 \pm 1 \mathrm{MPa}$ and $202 \pm 2 \mathrm{MPa}$, equivalent to $74.4 \%$ and $80.8 \%$ of $\mathrm{BM}(250 \mathrm{MPa})$, respectively. The larger tensile strength coincides with the larger hardness of the double-sided FSW. Figure 9 shows the fracture location of 
the single-sided FSW and the double-sided FSW. In the single-sided FSW, the fracture occurred in the HAZ of the advancing side. In the double-sided FSW, the crack initiated in the HAZ of the advancing side of the second pass and propagated to the HAZ of the retreating side of the first pass.
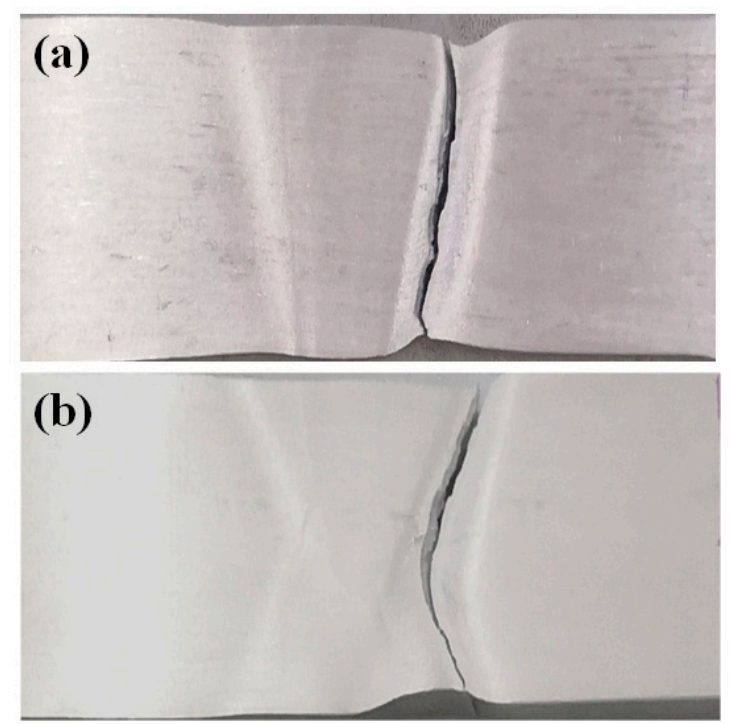

Figure 9. The fracture location of the single-sided FSW (a) and the double-sided FSW (b).

\subsection{Residual Stresses}

Figure 10 shows the residual stresses determined by neutron diffraction in the 6005A-T6 aluminium alloy single-sided and double-sided FSWs. In both specimens, the longitudinal and transverse residual stress distributions agreed with the typical ' $\mathrm{M}$ ' shape pattern of FSW aluminum alloys [6]. The normal residual stresses were observed with little variations, especially on L3 line of the single-sided FSW which remained near to a value of zero. Notably, the average uncertainty of the obtained stresses is approximately $\pm 13 \mathrm{MPa}$ in these measurements.
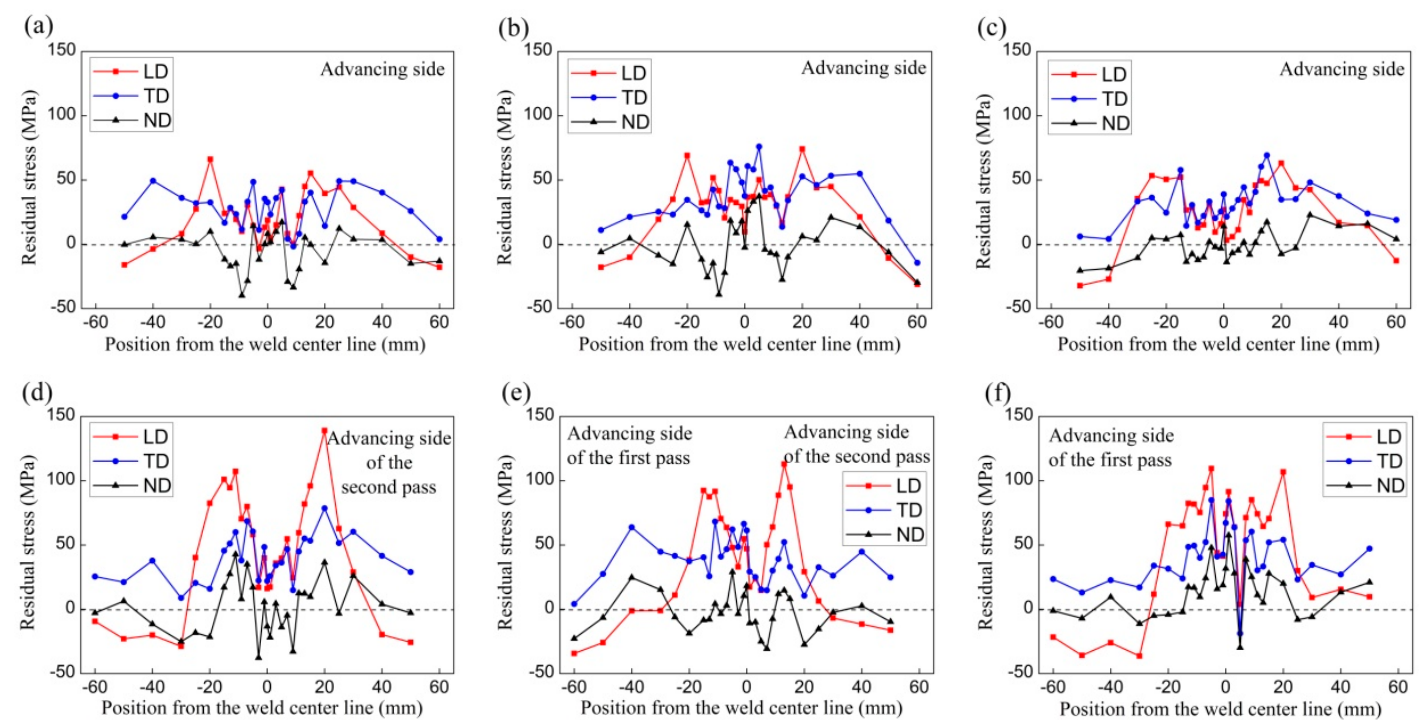

Figure 10. Residual stresses on L1 (a), L2 (b), L3 (c) in the single-sided FSW and L1 (d), L2 (e), L3 (f) in the double-sided FSW. 


\subsubsection{Features in the Single-Sided FSW}

In the single-sided FSW, the residual stresses along the three lines have a similar distribution in both trend as well as magnitude. $\sigma_{\mathrm{LD}}$ is generally equal to $\sigma_{\mathrm{TD}}$ and larger than $\sigma_{\mathrm{ND}}$. The maximum tensile $\sigma_{\mathrm{LD}}$ and $\sigma_{\mathrm{TD}}$ are nearly the same, approximately $75 \mathrm{MPa}$. This stress value amounts to $37.5 \%$ of the yield strength of Al-6005A-T6 alloy, which is $200 \mathrm{MPa}$ at room temperature.

The introduction of residual stresses is inevitable due to severe thermomechanical deformation by FSW. Therefore, it is important to control the amount of residual stress. Hassan et al. reported an optimum combination of rotational and travel speeds that gave the best mechanical performance [11]. This optimum condition shifted to a higher rotational speed when the travel speed was increased. High heat input associated with low traverse and high rotation speeds leads to more extensive softening in the weld region, resulting in an overall reduction in the magnitude of the longitudinal residual stress. It seems difficult to get both optimized mechanical properties and residual stresses. However, the present 6005A-T6 single-sided FSW achieved an acceptable condition for comprising the mechanical properties with a tensile strength of $74.4 \%$ of $\mathrm{BM}$ and residual stresses with peak magnitudes of approximately $37.5 \%$ yield strength of BM.

\subsubsection{Features in the Double-Sided FSW}

In the double-sided FSW, $\sigma_{\mathrm{LD}}$ is generally larger than $\sigma_{\mathrm{ND}}$ and $\sigma_{\mathrm{TD}}$. There is large difference between $\sigma_{\mathrm{LD}}$ magnitudes on the three lines, as shown in Figure 11. The maximum tensile $\sigma_{\mathrm{LD}}$ is approximately $140 \mathrm{MPa}$ on L1 line $(x t=-10), 115 \mathrm{MPa}$ on L2 line $(x t=0)$ and $110 \mathrm{MPa}$ on L3 line $(x t=10)$ respectively. These stress values amount to $70 \%, 57.5 \%$ and $55 \%$ of the yield strength of $\mathrm{BM}$. The residual stress profiles of the L1 line and L2 line show obvious asymmetric distributions. The highest stresses of those lines occur on the advancing side of the NZ compared to the retreating side. The maximum residual stress in the upper weld zone is $140 \mathrm{MPa}, 27 \%$ larger than the bottom weld zone, where the stress is $110 \mathrm{MPa}$. As the parameters were the same for the first and second pass, an inference was made that the peak magnitude of residual stress produced by the first weld pass was approximately $140 \mathrm{MPa}$. The heat input by the second weld pass provided the post-treatment environment of stress relaxation for the first-pass weld zone.
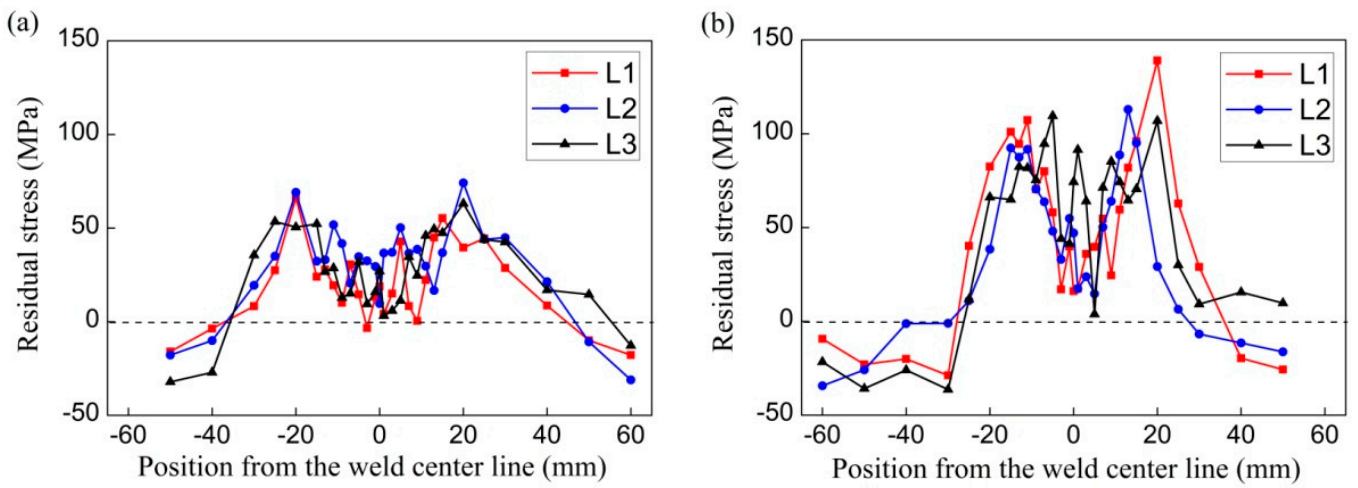

Figure 11. Replot of longitudinal residual stresses in a single-sided FSW (a) and a double-sided FSW(b).

Although the tensile strength of the double-sided FSW was a little higher than the single-side FSW, the longitudinal residual stresses in the double-sided FSW are much larger than the single-sided FSW, as shown in Figure 11.

\section{Summary and Conclusions}

In this study, residual stresses, microstructures and mechanical properties of the 6005A-T6 single-sided and double-sided FSWs were studied. The 3D residual stresses were characterized using neutron diffraction. The microstructures were observed by TEM and EBSD. 
In the 6005A-T6 single-sided FSW, there were acceptable mechanical properties with tensile strength $74.4 \%$ of $\mathrm{BM}$, and low residual stresses with peak magnitudes of approximately $37.5 \%$ yield strength of BM were achieved. This indicated a good quality of weld with such low residual stresses. However, good mechanical properties with a tensile strength of $80.8 \%$ of $\mathrm{BM}$, but high residual stresses with peak magnitudes of approximately $70 \%$ yield strength of BM were obtained in the $6005 \mathrm{~A}-\mathrm{T} 6$ double-sided FSW.

In the 6005A-T6 single-sided FSW, there was no precipitation in the NZ. The hardness of the $\mathrm{NZ}$ is related to the grain size. The less hardness at the upper NZ and high hardness at the bottom $\mathrm{NZ}$ coincided with the larger grain size at the upper NZ and smaller grain size at the bottom $\mathrm{NZ}$, respectively.

In the 6005A-T6 double-sided FSW, there were lower residual stresses and larger hardness in the first-pass weld zone, but higher residual stresses and smaller hardness in the second-pass weld zone. This was due to the heat input by the second weld pass which provided an aging environment for the first-pass weld zone, where the dissolved phases were precipitated and residual stresses were relaxed.

Author Contributions: Conceptualization, X.L. and H.Z.; investigation, P.X., R.W., R.L. and M.L.; Writing-Original Draft preparation, X.L.; Writing—Review and Editing, W.L., Y.L. and D.C.; funding acquisition, Y.L. and D.C.

Funding: This research activity was financially supported by Ministry of Science and Technology of China (grant 2017YFA0403704), National Natural Science Foundation of China (grants 11605293 and 51327902).

Conflicts of Interest: The authors declare no conflict of interest.

\section{References}

1. Simar, A.; Bréchet, Y.; De Meester, B.; Denquin, A.; Pardoen, T. Microstructure, local and global mechanical properties of friction stir welds in aluminium alloy 6005A-T6. Mater. Sci. Eng. A 2008, 486, 85-95. [CrossRef]

2. Ji, S.; Meng, X.; Liu, J.; Zhang, L.; Gao, S. Formation and mechanical properties of stationary shoulder friction stir welded 6005A-T6 aluminum alloy. Mater. Des. 2014, 62, 113-117. [CrossRef]

3. Lee, W.B.; Yeon, Y.M.; Jung, S.B. Evaluation of the microstructure and mechanical properties of friction stir welded 6005 aluminum alloy. Mater. Sci. Technol. 2003, 19, 1513-1518. [CrossRef]

4. Peng, D.; Hongmei, L.; Daqian, S.; Wenbiao, G.; Jie, L. Effects of welding speed on the microstructure and hardness in friction stir welding joints of 6005A-T6 aluminium alloy. Mater. Des. 2013, 45, 524-531.

5. Thomas, W.M.; Nicholas, E.D.; Needham, J.C.; Murch, M.G.; Temple-Smith, P.; Dawes, C.J. The Welding Institute, TWI. International Patent Application No. PCT/GB92/02203; GB Patent Application No. 9125978.8, 6 December 1991.

6. Threadgill, P.L.; Leonard, A.J.; Shercliff, H.R.; Withers, P.J. Friction stir welding of aluminium alloys. Int. Mater. Rev. 2009, 54, 49-93. [CrossRef]

7. Xu, W.; Liu, J.; Zhu, H. Analysis of residual stresses in thick aluminum friction welded butt joints. Mater. Des. 2011, 32, 2000-2005. [CrossRef]

8. Wang, X.L.; Feng, Z.; David, S.A.; Spooner, S.; Hubbard, C.R. Neutron diffraction study of residual stresses in friction stir welds. In Proceedings of the 6th International Conference on Residual stresses, Oxford, UK, 10-12 July 2000; pp. 1408-1414.

9. Haghshenas, M.; Gharghouri, M.A.; Bhakhri, V.; Klassen, R.J.; Gerlich, A.P. Assessing residual stresses in friction stir welding: Neutron diffraction and nanoindentation methods. Int. J. Adv. Manuf. Technol. 2017, 93, 3733-3747. [CrossRef]

10. Mehra, S.; Dhanda, P.; Khanna, R.; Goyat, N.S.; Verma, S. Effect of tool on tensile strength in single and double sided friction stir welding. Int. J. Sci. Eng. Res. 2012, 3, 1-6.

11. Hassan, K.A.; Prangnell, P.B.; Norman, A.F.; Price, D.A.; Williams, S.W. Effect of welding parameters on nugget zone microstructure and properties in high strength aluminium alloy friction stir welds. Sci. Technol. Weld. Join. 2003, 8, 257-268. [CrossRef]

12. Meng, X.; Gao, S.; Ma, L.; Li, Z.; Yue, Y.; Xiao, H. Effects of rotational velocity on microstructures and mechanical properties of surface compensation friction stir welded 6005A-T6 aluminum alloy. Eng. Rev. 2016, 36, 107-113. 
13. Sakala, R.S.; Renangi, S.; Indira, R.M. Experimental study of double sided friction stir welding of AA 6061 plates using hexagonal tool tip. Int. J. Res. Advent Technol. 2018, 6, 32-37.

14. Asgar, K.; Abdul, S.M.K.; Bharat, K. Fabrication of a butt joint using friction stir welding (FSW) -A non consumable tool to generate heat. Int. J. Res. Sci.Innov. 2016, 3, 53-55.

15. Woo, W.; Feng, Z.; Wang, X.L.; Brown, D.W.; Clausen, B.; An, K.; Choo, H.; Hubbard, C.R.; David, S.A. In situ neutron diffraction measurements of temperature and stresses during friction stir welding of 6061-T6 aluminium alloy. Sci. Technol. Weld. Join. 2007, 12, 298-303. [CrossRef]

16. Simar, A.; Bréchet, Y.; De Meester, B.; Denquin, A.; Gallais, C.; Pardoen, T. Integrated modeling of friction stir welding of 6xxx series Al alloys: Process, microstructure and properties. Prog. Mater. Sci. 2012, 57, 95-183. [CrossRef]

17. Liu, H.; Yang, S.; Xie, C.; Zhang, Q.; Cao, Y. Microstructure characterization and mechanism of fatigue crack initiation near pores for 6005A CMT welded joint. Mater. Sci. Eng. A 2017, 707, 22-29. [CrossRef]

18. Dong, P.; Sun, D.; Wang, B.; Zhang, Y.; Li, H. Microstructure, microhardness and corrosion susceptibility of friction stir welded AlMgSiCu alloy. Mater. Des. 2013, 54, 760-765. [CrossRef]

19. Feng, Z.; Wang, X.L.; David, S.A.; Sklad, P.S. Modeling of residual stresses and property distributions in friction stir welds of aluminum alloy 6061-T6. Sci. Technol. Weld. Join. 2013, 12, 348-356. [CrossRef]

20. Woo, W.; Feng, Z.; Wang, X.L.; David, S. Neutron diffraction measurements of residual stresses in friction stir welding: A review. Sci. Technol. Weld. Join. 2011, 16, 23-32. [CrossRef]

21. Malopheyev, S.; Vysotskiy, I.; Kulitskiy, V.; Mironov, S.; Kaibyshev, R. Optimization of processing-microstructure-properties relationship in friction-stir welded 6061-T6 aluminum alloy. Mater. Sci. Eng. A 2016, 662, 136-143. [CrossRef]

22. Deplus, K.; Simar, A.; Van Haver, W.; De Meester, B. Residual stresses in aluminium alloy friction stir welds. Int. J. Adv. Manuf. Technol. 2011, 56, 493-504. [CrossRef]

23. Simar, A.; Bréchet, Y.; De Meester, B.; Denquin, A.; Pardoen, T. Sequential modeling of local precipitation, strength and strain hardening in friction stir welds of an aluminum alloy 6005A-T6. Acta Mater. 2007, 55, 6133-6143. [CrossRef]

24. Tao, W.; Yong, Z.; Xuemei, L.; Matsuda, K. Special grain boundaries in the nugget zone of friction stir welded AA6061-T6 under various welding parameters. Mater. Sci. Eng. A 2016, 671, 7-16. [CrossRef]

25. Węglowski, M.S.; Sędek, P.; Hamilton, C. The effect of process parameters on residual stress in a Friction stir processed cast aluminium alloy. Eng. Trans. 2016, 64, 301-309.

26. Prime, M.; Gnaupel-Herold, T.; Baumann, J.; Lederich, R.; Bowden, D.; Sebring, R. Residual stress measurements in a thick, dissimilar aluminum alloy friction stir weld. Acta Mater. 2006, 54, 4013-4021. [CrossRef]

27. Sepe, R.; Armentani, E.; Di Lascio, P.; Citarella, R. Crack Growth Behavior of Welded Stiffened Panel. Procedia Eng. 2015, 109, 473-483. [CrossRef]

28. Citarella, R.; Carlone, P.; Lepore, M.A.; Sepe, R. Hybrid technique to assess the fatigue performance of multiple cracked FSW joints. Eng. Fract. Mech. 2016, 162, 38-50. [CrossRef]

29. Citarella, R.; Carlone, P.; Sepe, R.; Lepore, M.A. DBEM crack propagation in friction stir welded aluminum joints. Adv. Eng. Softw. 2016, 101, 50-59. [CrossRef]

30. Patel, V.; Li, W.; Wang, G.; Wang, F.; Vairis, A.; Niu, P. Friction Stir Welding of Dissimilar Aluminum Alloy Combinations: State-of-the-Art. Metals 2019, 9, 270. [CrossRef]

31. Sonne, M.R.; Carlone, P.; Hattel, J.H. Assessment of the Contour Method for 2-D Cross Sectional Residual Stress Measurements of Friction Stir Welded Parts of AA2024-T3-Numerical and Experimental Comparison. Metals 2017, 7, 508. [CrossRef]

32. Fadaeifard, F.; Matori, K.A.; Aziz, S.A.; Zolkarnain, L.; Rahim, M.A.Z.B.A.; Rahim, M.A. Effect of the Welding Speed on the Macrostructure, Microstructure and Mechanical Properties of AA6061-T6 Friction Stir Butt Welds. Metals 2017, 7, 48. [CrossRef]

33. Li, S.; Chen, Y.; Kang, J.; Amirkhiz, B.S.; Nadeau, F. Effect of Revolutionary Pitch on Interface Microstructure and Mechanical Behavior of Friction Stir Lap Welds of AA6082-T6 to Galvanized DP800. Metals 2018, 8, 925. [CrossRef]

34. Niu, P.; Li, W.; Zhang, Z.; Yang, X. Global and local constitutive behaviors of friction stir welded AA2024 joints. J. Mater. Sci. Technol. 2017, 33, 987-990. [CrossRef] 
35. Hutchings, M.T.; Withers, P.J.; Holden, T.M.; Lorentzen, T. Introduction to the Characterization of Residual Stress by Neutron Diffraction, 1st ed.; Taylor and Francis: London, UK, 2005.

36. Liu, X.; Wimpory, R.C.; Gong, H.; Liu, Y.; Chen, D.; Liu, Y.; Wu, Y.; Li, C. The Determination of Residual Stress in Quenched and Cold-Compressed 7050 Aluminum Alloy T-Section Forgings by the Contour Method and Neutron Diffraction. J. Mater. Eng. Perform. 2018, 27, 6049-6057. [CrossRef]

37. Wimpory, R.; Mikula, P.; Šaroun, J.; Poeste, T.; Li, J.; Hofmann, M.; Schneider, R. Efficiency Boost of the Materials Science Diffractometer E3 at BENSC: One Order of Magnitude Due to a Horizontally and Vertically Focusing Monochromator. Neutron News 2008, 19, 16-19. [CrossRef]

38. Mishra, R.; Ma, Z.; Mishra, R. Friction stir welding and processing. Mater. Sci. Eng. R Rep. 2005, 50, 1-78. [CrossRef]

39. Qian, J.W.; Li, J.L.; Xiong, J.T.; Zhang, F.S.; Li, W.Y.; Lin, X. Periodic variation of the torque and its relations to interfacial sticking and slipping during friction stir welding. Sci. Technol. Weld. Join. 2012, 17, 338-341. [CrossRef]

40. Randau, C.; Garbe, U.; Brokmeier, H.G. StressTextureCalculator: A software tool to extract texture, strain and microstructure information from area-detector measurements. J. Appl. Crystallogr. 2011, 44, 641-646. [CrossRef]

41. Gnäupel-Herold, T. ISODEC: Software for calculating diffraction elastic constants. J. Appl. Crystallogr. 2012, 45, 573-574. [CrossRef]

(C) 2019 by the authors. Licensee MDPI, Basel, Switzerland. This article is an open access article distributed under the terms and conditions of the Creative Commons Attribution (CC BY) license (http://creativecommons.org/licenses/by/4.0/). 